\title{
Prelog Lecture 2003
}

\author{
Eidgenössische Technische Hochschule Zürich \\ Laboratorium für Organische Chemie
}

\begin{abstract}
On Monday, November 10, 2003, the vice-president, Prof. Dr. Gerhard Schmitt, presented the Prelog Medal 2003 to Prof. Dr. Andreas Pfaltz, Department of Chemistry, University of Basel, Switzerland. The title of the lecture that followed was 'Design of Chiral Ligands for Asymmetric Catalysis'.
\end{abstract}

Keywords: Pfaltz, A. · Prelog Lecture

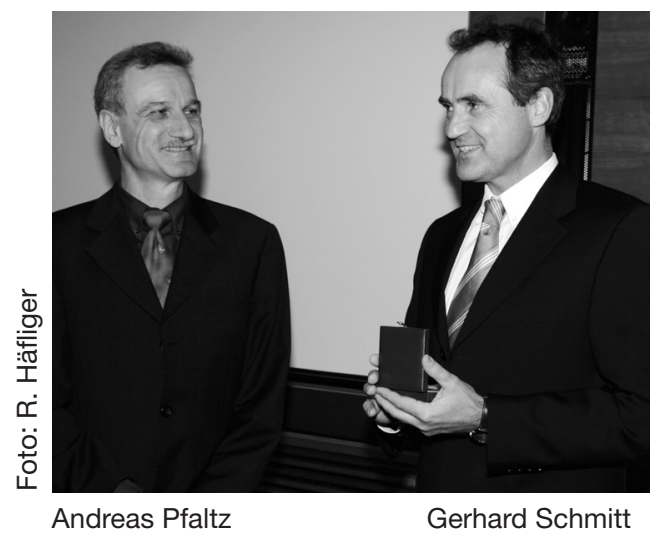

The 2003 Prelog Medal Winner, Prof. Dr. Andreas Pfaltz, was born in Basel, Switzerland in 1948. He carried out his diploma and doctoral studies at ETH Zürich under the direction of Prof. Dr. A. Eschenmoser, obtaining his doctoral degree in 1978. Professor Pfaltz subsequently furthered his professional training as a post-doctoral fellow at Columbia University working with Prof. Dr. Gilbert Stork. From 1980-1986 he was a member of the scientific staff at ETH Zürich. He held an appointment as Privatdozent from 1987-1990 at the same institution before accepting a position as associate professor at the University of Basel in 1990. Rapidly rising through the academic ranks, he was promoted to professor of organic chemistry in 1993 at the University of Basel. From 1995-1998 he held a prestigious appointment as a director at the MaxPlank-Institut für Kohlenforschung at Mülheim-Ruhr in Germany where he served as head of the homogeneous catalysis section.

In 1999 he returned to the position of professor of organic chemistry at the University of Basel, where he currently has an active, prolific program in chemistry. His outstanding contributions to organic chemistry have been recognized with numerous awards, such as the Werner Prize of the Swiss Chemical Society (1989), the Wilhelm Manchot Research Professorship at TU-München (2002), and the Pracejus Prize of the German Chemical Society (2003).

Professor Pfaltz has established a broad-based research program in chemistry that spans the disciplines of heterogeneous/homogeneous catalysis as well as asymmetric synthesis, with substantial impact for the preparation of biologically active substances such as pharmaceuticals, fragrances, and crop protective agents. He is a pioneer in the discovery and development of new families of optically active ligands for catalytic asymmetric synthesis.

Of significance in his early work was the discovery of bisoxazoline ligands, which he elegantly demonstrated were useful in a number of catalytic asymmetric processes. The speed with which a number of research groups world-wide in the Americas, Asia, and Europe successfully adopted these privileged structures into their own research endeavors attests to the importance and impact of these early observations and discoveries in the field of asymmetric catalysis. Ligand discovery and design is a theme that continues to thrive in Professor Pfaltz's laboratories to include new families of innovative ligands for a variety of challenging processes in catalysis such as asymmetric olefin reduction.

Unique to Professor Pfaltz's research program is the coupling of reaction discovery with mechanistic understanding that is linked to his quest for novel ligands with which to control and channel in useful di- rections the reactivity of transition-metal complexes. In addition to his program in homogeneous catalysis Professor Pfaltz has made significant contributions in heterogeneous catalysis, as evidenced by his extensive publications in this area and collaborative efforts with industry and academic groups. His scientific work is immediately recognizable as a result of its high quality, innovation, and scholarship.

\section{Former Prelog Lecturers}

1986 Kurt Mislow

1987 Meier Lahav and

Leslie Leiserowitz

1988 K. Barry Sharpless

1989 Jeremy R. Knowles

1990 Henri B. Kagan

1991 Clayton H. Heathcock

1992 J. Michael McBride

1993 Hisashi Yamamoto

1994 Jean-Pierre Sauvage

1995 Yoshito Kishi

1996 David M.J. Lilley

1997 Günter Helmchen

1998 Lia Addadi

1999 David Evans

2000 Helmut Schwarz

2001 Robert H. Grubbs

2002 David E. Cane 